\title{
Reflexões a respeito das relações de emprego em época de pandemia da COVID-19
}

\author{
Reflections on employment relations at a time of the COVID-19 pandemic \\ Reflexiones sobre las relaciones laborales en tiempos de la pandemia del COVID-19
}

Ricardo Ovídio de Oliveira Lima

ORCID: https://orcid.org/0000-0002-1645-7537 Faculdade São Vicente de Pão de Açúcar, Brasil

Universidade Potiguar, Brasil

E-mail: ricardooliveira-adv@hotmail.com

Thalita Kelle Pires Beserra

ORCID: https://orcid.org/0000-0003-2693-8702

Faculdade São Vicente de Pão de Açúcar, Brasil Universidade Potiguar, Brasil E-mail: tpiresb@gmail.com

Pedro Victor Miranda de Oliveira

ORCID: https://orcid.org/0000-0003-0478-8766 Universidade Estadual do Piauí, Brasil

E-mail: pedrovictormiranda48@gmail.com

Jhonatha Magalhães Silva

ORCID: https://orcid.org/0000-0002-8120-8713

Christus Faculdade do Piauí, Brasil

E-mail:jhonathamagalhaes0708@gmail.com

Jose Rosman Varjão Alves de Albuquerque

ORCID: https://orcid.org/0000-0003-4097-4478

UniRios, Brasil

E-mail: j.rosman.albuquerque@ @otmail.com

Isabele Thalyta Oliveira Andrade

ORCID: https://orcid.org/0000-0001-6771-3652 UniRios, Brasil

E-mail: isabelethalyta.adv@gmail.com Nilton Soares Formiga

ORCID: https://orcid.org/0000-0003-4907-9736

Universidade Potiguar, Brasil

E-mail: nsformiga@yahoo.com

\begin{abstract}
Resumo
A pandemia originada da COVID-19 trouxe para o direito brasileiro diversos desafios, principalmente em relação ao direito do trabalho, precisando se adequar ao "novo normal" onde a jornada de trabalho é mais reduzida, consequentemente gerando a diminuição salários e afetando a economia gerando desempregos devido as medidas restritivas tomadas pela União, Estados e Municípios, firmando a necessidade de garantir para a parcela da população que não possui um emprego uma fonte de renda e a necessidade da manutenção dos empregos que foram mantidos através de políticas sociais. A compreensão de como o direito do trabalho foi impactado durante esse período é o principal objetivo desse estudo, e como Estado conseguiu lidar e tentar garantir a população economicamente ativa meios de contornar essas intempéries, utilizando para a análise do fenômeno a bibliografia, através de uma pesquisa bibliográfica com abordagem qualitativa principalmente com relação a doutrina e as leis e decretos sancionados no período, fazendo uso assim do método indutivo para chegar no resultado de que as leis e decretos foram responsáveis por impactar e mudar as leis trabalhistas, além de garantir benefícios assistencialistas a população em situação de vulnerabilidade.
\end{abstract}

Palavras-chave: COVID-19; Direito do trabalho; Aviso prévio; Auxílio emergencial.

\section{Abstract}

The pandemic originated from COVID-19 brought to Brazilian law several challenges, especially in relation to labor law, needing to adapt to the "new normal" where the working day is shorter, consequently generating lower wages and affecting the economy. unemployment due to restrictive measures taken by the Union, States and Municipalities, establishing the need to guarantee a source of income for the part of the population that does not have a job and the need to maintain the jobs that were maintained through social policies. The understanding of how labor law was impacted during this period is the main objective of this study, and how the State managed to deal and try to guarantee the economically active population ways to circumvent these storms, using the bibliography for the analysis of the 
phenomenon, through a bibliographical research with a qualitative approach, mainly in relation to doctrine and laws and decrees sanctioned in the period, thus making use of the inductive method to reach the result that laws and decrees were responsible for impacting and changing labor laws, in addition to ensuring welfare benefits the population in a vulnerable situation.

Keywords: COVID-19; Labor law; Prior notice; Emergency aid

\section{Resumen}

La pandemia originada por el COVID-19 trajo a la legislación brasileña varios desafíos, especialmente en relación al derecho laboral, necesitando adaptarse a la "nueva normalidad" donde la jornada de trabajo es más reducida, generando consecuentemente la disminución de los salarios y afectando la economía generando desempleo debido a las medidas restrictivas tomadas por la Unión, Estados y Municipios, estableciendo la necesidad de asegurar para la porción de la población que no tiene trabajo una fuente de ingresos y la necesidad de mantener los empleos que fueron mantenidos a través de políticas sociales. La comprensión de cómo el derecho al trabajo fue impactado durante este período es el principal objetivo de este estudio, y cómo el Estado logró lidiar e intentar asegurar a la población económicamente activa medios para sortear estas tormentas, utilizando para el análisis del fenómeno la bibliografía, a través de una investigación bibliográfica con enfoque cualitativo principalmente con respecto a la doctrina y a las leyes y decretos sancionados en el periodo, haciendo así uso del método inductivo para llegar al resultado de que las leyes y decretos fueron los responsables de impactar y cambiar las leyes laborales, además de garantizar beneficios asistenciales a la población en situación de vulnerabilidad.

Palabras clave: COVID-19; Derecho laboral; Aviso previo; Ayuda de emergencia.

\section{Introdução}

Com o cenário mundial atualmente modificado social, política e economicamente, devido a Pandemia causada pela COVID-19, diversos foram os setores que sofreram com impacto das mudanças advindas por este cenário, dentre estes, o espaço do mundo do trabalho foi aquele que se exigiu maior adaptação a esta 'nova rotina'. Neste contexto, destaca-se o antagonismo direito versus dever entre os empregadores e os trabalhadores; estes, duas partes distintas, porém, ambas tiveram suas necessidades destacadas durante o período pandêmico, momento em que os trabalhadores necessitavam trabalhar e receber seu salário para sobreviverem, e em contrapartida, os empregadores necessitavam cortar gastos para minimizar seus prejuízos.

Assumido, à época, uma situação caótica devido ao coronavírus, vários institutos jurídicos não foram seguidos, de modo que não tiveram sua aplicação na realidade fática, o que gerou prejuízo aos trabalhadores, pois tiveram alguns de seus direitos cerceados. Vale lembrar que a pandemia foi uma situação excepcional, instituída a fim de inibir a contaminação em massa gerada pela COVID-19, razão pela qual os empregadores, com receio dos altos prejuízos, provocaram uma demissão de grande parte de seu pessoal. A partir disso, reflete-se: Quais os principais impactos causados no Direito do Trabalho durante a Pandemia da COVID-19?

Destaca-se a importância de estudos na respectiva temática, não apenas para a dimensão da sociedade em geral, mas, também, para à academia, ciência social e humana e o mundo do trabalho, haja vista que, apesar da pouca repercussão sobre os direitos trabalhista e da função social do trabalho a prática das demissões se deu em grande escala, o que gerou prejuízo aos trabalhadores, de modo que um estudo aprofundado sobre os principais impactos causados na seara trabalhista se faz necessária. Apesar de todo o ocorrido, não se pode esquecer que o conceito de dignidade da pessoa humana se encaixa como uma luva no âmbito de qualquer relação de trabalho, sobretudo na relação empregatícia, tendo em vista o estado de subordinação a que fica submetido o empregado diante do poder empregatício do tomador dos seus serviços (Leite, 2020).

O estudo ora apresentado tem como objetivo analisar o impacto da pandemia no direito do trabalho, apresentando como objetivos específicos, um breve estudo sobre o impacto da pandemia no aviso prévio e a aplicação do auxílio emergencial como uma forma de garantir as pessoas desempregadas o mínimo existencial. 


\section{Metodologia}

Em relação a metodologia utilizada na pesquisa, teve como intuito contribuir para alcançar os objetivos proposto na pesquisa, bem como resolver a solução da pergunta norteadora, sendo assim, a metodologia usada do estudo fora uma pesquisa bibliográfica com abordagem qualitativa.

Usando coletas de dados de experiências vividas pelos autores, buscando verificar as ideias trazidas pelos autores e confrontá-las com os objetivos e a problemática do estudo, discutindo as repercussões jurídicas da pandemia, com um olhar voltado no aviso prévio e auxílio emergencial.

De acordo com Lakatos e Marconi (2010), os métodos de pesquisa utilizado para o presente estudo sugere que o pesquisador se associe, diretamente, com o que foi escrito, dito ou filmado sobre determinado assunto, inclusive as conferências seguidas de debates que tenham sido transcritos por algumas formas, querem publicadas, quer gravadas.

Ou seja, a partir do contato direto do pesquisador com o tema que ele está pesquisando, torna a explanação do conteúdo em seu trabalho muito mais cristalina, haja vista que as informações colhidas foram retiradas diretamente das fontes que já tinham noção daquele determinado assunto, dessa forma o acadêmico tem mais possibilidade de ministrar aquele determinado conteúdo com mais propriedade.

Com as pesquisas bibliográficas, foi possível explicitar os fins que o presente trabalho visava, isto é, tornou possível a observação dos impactos no Direito do Trabalho com a implementação da pandemia, com um enfoque maior no aviso prévio e auxílio emergencial durante o ano de 2020.

Ainda sobre a pesquisa bibliográfica, é notória sua relevância para enriquecer a pesquisa do autor como mencionado acima, e sobre tal pensamento, Fonseca (2002, p. 32) aduz que

A pesquisa bibliográfica é feita a partir do levantamento de referências teóricas já analisadas, e publicadas por meios escritos e eletrônicos, como livros, artigos científicos, páginas de web sites. Qualquer trabalho científico inicia-se com uma pesquisa bibliográfica, que permite ao pesquisador conhecer o que já se estudou sobre o assunto. Existem, porém pesquisas científicas que se baseiam unicamente na pesquisa bibliográfica, procurando referências teóricas publicadas com o objetivo de recolher informações ou conhecimentos prévios sobre o problema a respeito do qual se procura a resposta.

Percebe-se que, com o método da pesquisa bibliográfica, é possível tornar o trabalho rico, pois as argumentações do autor da pesquisa serão consubstanciadas nas ideias, pesquisas e projetos já realizados por outros autores, fomentando assim o resultado que o autor inicialmente pretendia chegar.

Para o estudo bibliográfico foram utilizados artigos científicos, e legislação jurídica brasileira, a exemplo da PEC $\mathrm{n}^{\circ}$ 10/2020 e da lei 13.979/2020, também foi usada a mais recente doutrina, assim a pesquisa foi restrita, pois os materiais selecionados para pesquisados foram somente aqueles que tratassem dos impactos causados no Direito do Trabalho e tivesse objetivos semelhantes.

\section{Resultados e Discussão}

\subsection{Principais impactos da pandemia no direito do trabalho}

Ao discorrer sobre os principais impactos causados no Direito do Trabalho durante a Pandemia da COVID-19, tornase indispensável falar também sobre a questão do aviso prévio e a implementação do auxílio emergencial, que de certa forma, ajudou as famílias que perderam a sua fonte de renda.

É consabido que com a decretação de pandemia, houve o declínio no que diz respeito o modo de vida da população mundial, tendo que em vista que atingiu de forma surpreendente, causando prejuízo e impacto estes que se alastraram, não 
importasse o tipo de isolamento seguido pelos países. No caso do Brasil, o isolamento implementado foi o horizontal, consistente em que o maior número de pessoas deve permanecer em suas residências, não importando se apresentam ou não fatores de risco ou não para a doença, com a finalidade de evitar a disseminação do vírus.

O outro tipo de isolamento é o vertical, sendo este, consistente em que apenas os grupos de risco deverão permanecer em casa, tais como idosos, cardiopatas, hipertensos, diabéticos, dentre outros. Contudo, a economia mundial foi profundamente afetada, visto que os novos modos de trabalhar e produzir, bem como a redução dos padrões de consumo, geraram o empobrecimento e entravamento à economia, situações desenvolvidas pelas regras instituídas pelas barreiras sanitárias (isolamento).

Cumpre ressaltar que a Lei $\mathrm{n}^{\circ}$ 13.979/2020 autorizou medidas para conter a disseminação ao novo coronavírus, pois, em seu artigo $3^{\circ}$, dispõe sobre o isolamento, quarentena e a determinação obrigatória de exames. Na data de 12 de março de 2020 foi publicada a Portaria n ${ }^{\circ}$ 356/2020 pelo Ministério da Saúde, momento em que regulamenta estas medidas.

Com isso, Estados e Municípios determinaram o fechamento de parques, praias, lojas e até mesmo rodovias, visando a defesa dos munícipes. Porém, na data de 20 de março de 2020, o Decreto Presidencial no 10.282/2020 definiu os serviços públicos e atividades essenciais. Ainda, nesta mesma data, o Congresso Nacional decretou estado de calamidade pública, através do Decreto Legislativo no 6/2020.

Faz-se necessário falar também sobre o instituto do Aviso Prévio, disposto nos artigos 487 a 491 da Consolidação das Leis do Trabalho (CLT), mas principalmente em sua aplicação através do Benefício Emergencial de Preservação do Emprego e Renda.

\subsection{Aviso prévio na pandemia}

Por definição o aviso prévio é um prazo temporal, sendo um meio entre a denúncia contratual e o término do contrato. A origem do instituto do aviso prévio remonta a época da idade média, onde nas corporações de ofício os companheiros forneciam previamente ao mestre um aviso prévio de que se afastariam do trabalho, porém o direito ao aviso prévio não era mútuo, já que o mestre poderia demitir o companheiro sem qualquer tipo de aviso.

No Brasil, a primeira vez que se ouviu falar nesse instituto foi no código comercial, onde na regência dos contratos entre preponentes e prepostos era previsto o aviso prévio de um mês. Além disso o código civil de 1916 também previa ordenamentos no mesmo sentido, mas o sistema normativo jurídico pioneiro na concessão de aviso prévio no país foi o Decreto $n^{\circ} 16.107 / 23$ que normatizou o aviso em contratos de tempo determinado, essas regulações perduraram até a criação da CLT que rege o aviso prévio do art. 487 ao art. 491, ainda sendo disposto constitucionalmente na Carta Magna de 1988. (Cassar, 2017)

Com a decretação da pandemia, houve a necessidade de mudanças de regras na legislação trabalhista, já que os três setores da economia se mostraram frágeis diante do problema causado pela COVID-19, e para limitar o contágio entre pessoas se fez necessária a adoção de medidas restritivas, que tiveram duras consequências para a economia. Como o fechamento de indústrias, comércios, lojas, shopping centers, seja por falência, já que as restrições retiraram o poder aquisitivo e a capacidade de autogestão das empresas, seja apenas por limitação de funcionamento por horário, deixando claro que a relação empregador-empregado chegou a um patamar diferente nesse momento.

Uma das medidas que tiveram por meta sanar esse problema foi a lei $\mathrm{n}^{\circ}$ 14.020/2020, que criou o Benefício Emergencial de Preservação do Emprego e da Renda, que teve por objetivo principal a assistência dos empregados que tiveram seus contratos de trabalhos suspensos ou suas jornadas reduzidas por conta da pandemia com o intuito de ajudar os empregadores complementando o salário do empregado, enquanto o período de Estado de Calamidade Pública estivesse vigendo. 
Dito isto, a lei 14.020/2020 foi muito vantajosa para os empregados que estavam passando pela etapa de aviso prévio, já que o Art. 23 da lei disciplina o benefício para esses empregados, citando que o empregador e empregado podem, em comum acordo, optar pelo cancelamento de aviso prévio em curso.

O mesmo artigo ratifica o mencionado no seu parágrafo único, em caso de cancelamento do aviso prévio nos termos deste artigo, as partes podem, na forma desta Lei, adotar as medidas do Programa Emergencial de Manutenção do Emprego e da Renda. (Brasil, 2020)

Ora, de acordo com o artigo 23, caso as duas partes decidam pelo cancelamento do aviso prévio, o contrato de trabalho por tempo indeterminado continua a sua vigência normal, com a diferença de que há a adesão no Programa Emergencial, ficando a cargo do empregador a entrega de documentação em tempo hábil para a sua regularização no programa para que o empregado possa receber sua compensação financeira. Em um período em que o desemprego aumentou desenfreadamente, o cancelamento do aviso prévio acaba por garantir ao trabalhador uma sobrevida em seu trabalho e uma nova chance de se estruturar financeiramente.

\subsection{Auxílio emergencial}

O auxílio emergencial surge do mesmo modo que o Benefício Emergencial de Preservação do Emprego e Renda, como um benefício advindo da situação de Calamidade Pública que foram instituídas pela lei 13.979/2020 e pelo decreto legislativo $n^{\circ}$ 06/2020, o auxílio emergencial foi criado pela lei $n^{\circ} 13.982 / 2020$ que estabeleceu as medidas a serem adotadas enquanto prevalecesse o período de emergência, que segundo o Decreto Legislativo seria até o dia 31 de dezembro de 2020.

Segundo o art. $2^{\circ}$ da lei que instituiu o Auxílio Emergencial, foi concedido ao trabalhador o auxílio no valor de 600 (seiscentos) reais, para aqueles que preenchessem os seguintes requisitos, como mostra (Brasil, 2020):

Art. $2^{\circ}$ Durante o período de 3 (três) meses, a contar da publicação desta Lei, será concedido auxílio emergencial no valor de $\mathrm{R} \$ 600,00$ (seiscentos reais) mensais ao trabalhador que cumpra cumulativamente os seguintes requisitos: I - seja maior de 18 (dezoito) anos de idade, salvo no caso de mães adolescentes; (Redação dada pela Lei nº 13.998, de 2020)

II - não tenha emprego formal ativo;

III - não seja titular de benefício previdenciário ou assistencial ou beneficiário do seguro-desemprego ou de programa de transferência de renda federal, ressalvado, nos termos dos $\S 1^{\circ}$ e $2^{\circ}$, o Bolsa Família;

IV - cuja renda familiar mensal per capita seja de até $1 / 2$ (meio) salário-mínimo ou a renda familiar mensal total seja de até 3 (três) salários mínimos;

V - que, no ano de 2018, não tenha recebido rendimentos tributáveis acima de R\$28.559,70 (vinte e oito mil, quinhentos e cinquenta e nove reais e setenta centavos); e

VI - que exerça atividade na condição de:

a) microempreendedor individual (MEI);

b) contribuinte individual do Regime Geral de Previdência Social que contribua na forma do caput ou do inciso I do $\S$ $2^{\circ}$ do art. 21 da Lei ${ }^{\circ} 8.212$, de 24 de julho de 1991 ; ou

c) trabalhador informal, seja empregado, autônomo ou desempregado, de qualquer natureza, inclusive o intermitente inativo, inscrito no Cadastro Único para Programas Sociais do Governo Federal (CadÚnico) até 20 de março de 2020, ou que, nos termos de autodeclaração, cumpra o requisito do inciso IV.

Percebe-se aqui o perfil das pessoas que podem receber o benefício, como mostra o segundo requisito que é o de não ter um emprego formal ativo, já que o caráter do benefício é justamente promover através de ações estatais a movimentação da economia. Diferentemente do Auxílio emergencial, o programa de preservação de emprego e renda, se destinava aqueles que já tinham um emprego formal e que viam sua fonte de renda ameaçada pela pandemia, já com o Auxílio Emergencial as famílias que possuíssem o Cadastro Único do Governo Federal, que tivessem renda bem abaixo do mínimo e que não recebessem benefícios previdenciários e assistenciais poderiam prover as suas famílias um mínimo existencial.

Além disso o auxílio já foi pago diretamente a mais de 66 milhões de pessoas segundo, que representa quase um terço 
da população brasileira. (Brasil, 2020) Claro que os valores pagos pelo auxílio emergencial estão longe de representar um valor ideal para que a população possa suprir suas necessidades mensais, mas os beneficiários a receber estão em situação de desemprego, o que nos dá duas situações, expondo que quase um terço da população brasileira está sem emprego e que mesmo sem emprego e com subsídio do governo federal há dinheiro no bolso e comida na mesa.

A natureza jurídica da prestação pecuniária é de benefício eventual assistencial, independente assim de contribuição à seguridade social para poder ser contemplado pelas parcelas do auxílio (Garcia, 2021). Desta maneira, é importante saber disso já que não há como esperar uma contraprestação das pessoas que receberam o auxílio, visto que a grande maioria é parte hipossuficiente na relação, caso contrário não precisariam dele para subsistir.

\section{Considerações Finais}

Entende-se que a partir do que foi exposto neste artigo pode-se comentar que o ano de 2020 foi um ano bastante atípico para todo o planeta. A pandemia da COVID-19 exigiu de todos um esforço, para que a diminuição do contágio se efetivasse de maneira firme. Isso fez com que o governo federal tivesse que adotar medidas a fim de salvaguardar a economia do país, além de preservar empregos e fornecer subsídios para aqueles que se encontrassem em uma situação de vulnerabilidade maior.

O maior impacto da pandemia no direito do trabalho foi alterar por via de decretos e leis, grande parte da legislação referente ao direito do trabalho, já que o perigo de contágio impediu a maior parte das pessoas de saírem de suas casas para trabalhar, com exceção dos serviços essenciais, além disso houve um número maior de benefícios assistenciais dados as pessoas, tanto para evitar as demissões, quanto para evitar mais prejuízos sociais como a fome e a miséria.

O aviso prévio teve suas hipóteses de cabimentos alteradas para que o número de demissões não explodisse no período pandêmico, além do auxílio emergencial que resguardou o mínimo existencial da população brasileira, impactando positivamente a economia do país.

Conclui-se que mais poderia ser feito para conter a doença e alavancar a economia e se fazem necessárias prestações positivas do Estado para que haja uma concretude ainda maior nas relações trabalhistas altamente impactadas pela pandemia, tendo em vista que ainda pode-se perceber a existência das necessidades, tanto do empregador, que precisa evitar maiores prejuízos, quanto do empregado, que necessita de trabalho para a sua subsistência e de sua família.

Os entendimentos reais de toda as alterações sociais que ocorreram durante a pandemia só conseguirão ser visualizadas com outros estudos, mas para o presente momento, as realizações foram as expostas.

\section{Referências}

Almeida, M., Fernandes, R., Lima, M., Miranda, S., Mise, Y., Santos, K. (2020). Trabalho, saúde e vulnerabilidade na pandemia de Covid-19. https://doi.org/10.1590/0102-311X00178320.

Assunção, C. S. de L. T., Assunção, M. V. D. de, Sousa, M. C. M. de, \& Oliveira, R. A. A. de. (2020). Um estudo relacional entre decretos governamentais e número de óbitos pela COVID-19 no Nordeste brasileiro. Research, Society and Development, 9(8), e379985550. https://doi.org/10.33448/rsd-v9i8.5550

Brasil (2020) Auxílio Emergencial chega a 60\% da população brasileira. https://www.gov.br/pt-br/noticias/financas-impostos-e-gestao-publica/600dias/arquivos-de-600-dias/cidadania-auxilio-emergencial-chega-a-60-da-populacao-brasileira>

Brasil. (2020). Lei n. 13.979. de 6 de fevereiro de 2020, para definir os serviços públicos e as atividades essenciais. <http://www.planalto.gov.br/ccivil_03/_ato2019-2022/2020/decreto/D10282.htm>

Brasil (2020). DECRETO LEGISLATIVO Nº 6, DE 2020. Reconhece, para fins do art. 65 da Lei Complementar $n^{\circ} 101$, de 4 de maio de 200, a ocorrência do estado de calamidade pública, nos termos da solicitação do Presidente da República encaminhada por meio da Mensagem nº 93 , de 18 de março de 2020. <http://www.planalto.gov.br/ccivil_03/portaria/DLG6-2020.htm> 
Research, Society and Development, v. 10, n. 15, e463101521783, 2021 (CC BY 4.0) | ISSN 2525-3409 | DOI: http://dx.doi.org/10.33448/rsd-v10i15.21783

Brasil. Lei $n^{\circ}$ 13.979, DE 6 DE FEVEREIRO DE 2020. Dispõe sobre as medidas para enfrentamento da emergência de saúde pública de importância internacional decorrente do coronavírus responsável pelo surto de 2019. <http://www.planalto.gov.br/ccivil_03/_ato2019-2022/2020/lei/113979.htm>

Brasil (2020). Lei $n^{o}$ 13.982, DE 2 DE ABRIL DE 2020. Altera a Lei $n^{\circ}$ 8.742, de 7 de dezembro de 1993, para dispor sobre parâmetros adicionais de caracterização da situação de vulnerabilidade social para fins de elegibilidade ao benefício de prestação continuada (BPC), e estabelece medidas excepcionais de proteção social a serem adotadas durante o período de enfrentamento da emergência de saúde pública de importância internacional decorrente do coronavírus (Covid-19) responsável pelo surto de 2019, a que se refere a Lei $n^{o} 13.979$, de 6 de fevereiro de 2020. <http://www.planalto.gov.br/ccivil_03/_ato2019-2022/2020/lei/113982.htm>

Brasil. (2020) Lei $n^{\circ}$ 14.020, DE 6 DE JULHO DE 2020. Institui o Programa Emergencial de Manutenção do Emprego e da Renda; dispõe sobre medidas complementares para enfrentamento do estado de calamidade pública reconhecido pelo Decreto Legislativo $n^{\circ} 6$, de 20 de março de 2020 , e da emergência de saúde pública de importância internacional decorrente do coronavírus, de que trata a Lei $n^{\circ} 13.979$, de 6 de fevereiro de 2020; altera as Leis $n$ os 8.213, de 24 de julho de 1991, 10.101, de 19 de dezembro de 2000, 12.546, de 14 de dezembro de 2011, 10.865, de 30 de abril de 2004, e 8.177, de $1^{\circ}$ de março de 1991; e dá outras providências..: <https://www.in.gov.br/en/web/dou/-/lei-n-14.020-de-6-de-julho-de-2020-265386938>

Brasil (2020). Portaria $n^{\circ}$ 356, DE 11 DE MARÇO DE 2020. Dispõe sobre a regulamentação e operacionalização do disposto na Lei $n^{\circ}$ 13.979, de 6 de fevereiro de 2020, que estabelece as medidas para enfrentamento da emergência de saúde pública de importância internacional decorrente do coronavírus (COVID-19). <https://www.in.gov.br/en/web/dou/-/portaria-n-356-de-11-de-marco-de-2020 247538346>

Bridi, M. (2020) A pandemia Covid-19: crise e deterioração do mercado de trabalho no Brasil. https://doi.org/10.1590/s0103-4014.2020.34100.010

Calvo, A. (2020) Manual de direito do trabalho. Saraiva Educação.

Cassar, V. (2017). Direito do trabalho. Método.

Fonseca, J. (2002) Metodologia da pesquisa científica. UEC.

Garcia, G. (2021). Coronavírus e Direito à Saúde: repercussões trabalhistas, previdenciárias e na assistência social. Saraiva Educação.

Filho, H., Mende, D.; Tellechea, J. (2020) A realidade do trabalho home office na atipicidade pandêmica. Revista Valore.

Lakatos, E., Marcone, M. (2003). Fundamentos de metodologia científica. Atlas.

Leite, C. (2020). Curso de direito do trabalho. Saraiva Educação.

Lima, R. O. de O., Beserra, T. K. P., Oliveira, P. V. M. de, Silva, J. M., Albuquerque, J. R. V. A. de, Melo, I. T. O. A., \& Formiga, N. S. (2021). A ingerência contratual e os danos a Administração Pública Municipal. Research, Society and Development, 10(14), e63101421575. https://doi.org/10.33448/rsdv10i14.21575

Lourencini, J. (2020). Medidas provisórias no âmbito do direito do trabalho em tempos de covid-19. https://jus.com.br/artigos/81763.

Martinez, L. (2020). Curso de direito do trabalho. (11a ed.), Saraiva Educação.

Nascimento, A. M. (2011). Curso de direito do trabalho: história e teoria geral do direito do trabalho: relações individuais e coletivas do trabalho. (26a ed.), Saraiva

Resende, R. (2020). Direito do trabalho. (8a ed.), Forense; MÉTODO

Souza, D. (2021). As dimensões da precarização do trabalho em face da pandemia de Covid-19. https://doi.org/10.1590/1981-7746-sol00311. 